\title{
Single and Multiplayer Video Gamers: Looking at Their Experiences and Psychosocial Well-Being During the COVID-19 Pandemic
}

\author{
Nathan N. Su${ }^{1}$ \\ ${ }^{1}$ Polygence Research Academy, 720 Serra Street, Suite 413, Stanford, CA 94305, USA \\ Correspondence: Nathan N. Su, Polygence Research Academy, 720 Serra Street, Suite 413, Stanford, CA 94305 , \\ USA.
}

Received: September 26, 2021

Accepted: November 1, 2021

Online Published: November 4, 2021

doi:10.5539/ijps.v13n4p51

URL: https://doi.org/10.5539/ijps.v13n4p51

\begin{abstract}
The COVID-19 pandemic has impacted our lives in many different ways. One significant impact on daily life was the increased indoor time due to quarantine measures. Data collected suggests video games have become more popular than ever during these unprecedented times (Epstein, 2020).

This study aims to explore the experiences and psychosocial well-being of individuals who played single and multiplayer video games during the pandemic.

Data was collected through a questionnaire distributed to multiple online communities and forums from June 28th to July 29th, 2021. The total collected responses were $n=260.132$ participants identified themselves as playing mostly single-player video games and 128 identified themselves as playing mostly multiplayer games.

The results show during the pandemic individuals spent more time playing both types of video games. Motivations for playing single-player games trended towards decreasing anxiety and stress, and avoiding real life, whereas multiplayer motivations tended to trend towards socialization rather than decreasing stress or anxiety. During the pandemic, $40-50 \%$ of single and multiplayer gamers indicated decreased mental health. However, both types of players reported improvement in mental and social well-being while playing video games. More multiplayer gamers reported improved social well-being while playing compared to single-player gamers.

The survey respondents tended to report having more positive experiences with single-player and multiplayer video games during the pandemic. Results presented video games as a way for individuals to socialize or decrease stress and anxiety. In addition, the comparison between the two types of gamers revealed that single-player respondents tended to play for relaxation, stress reduction, and perhaps improvement in mental health, while multiplayer gamers play to increase social interaction and improve social well-being.

Further research is needed to explore the long-term effects of video games during the pandemic after everyone has returned to a pre-pandemic state.
\end{abstract}

Keywords: COVID-19 pandemic, multiplayer, MMO, motivations, mental health, psychosocial well-being, single-player, video games

\section{Introduction}

The COVID-19 pandemic has greatly impacted the lives of most people. It has changed the way we work, go to school, socialize, and spend our free time. With shelter-in-place mandates and lockdowns, we rely on more indoor activities. One popular activity throughout the pandemic is playing video games. We can play them alone or with others online. Single-player video games are usually games played by one person. There may be single and multiplayer modes within the game, but the game itself only requires one player for it to work. Multiplayer, also called massively multiplayer online game (MMO), is an online video game in which a player interacts with other players, sometimes with many players in order to play.

Although prominent before the pandemic, the video game industry saw a huge boom in sales during COVID-19 (Epstein, 2020). One study suggests that video games have become more popular than ever (Smith, 2020). It is estimated that 3.24 billion people across the globe play video games (Clement, 2021). Whether people played before the pandemic or started to play during it, many have turned to video games. With popular titles like "Valorant," "Counter-Strike Global Offensive," and "Call of Duty: Warzone" snagging hundreds of thousands of 
concurrent players, it is clear to see the sheer number of people playing video games (Das, 2021; Hamstead, 2021; CS:GO Statistics, 2021). Past studies have shown both the negative and positive effects of gaming. This study aims to explore the experiences and psychosocial well-being of individuals who play single and multiplayer video games during the COVID-19 pandemic.

\section{Literature Review}

The review of existing literature revealed both negative and positive effects of video games. One review article looked at six studies involving online video games and found both helpful and harmful impacts on the psychosocial well-being of the population studied and depending on the methodologies used, sometimes only tentative conclusions can be made (Scott \& Porter-Armstrong, 2013). Other studies attempt to collect demographic and behavioral data of a large population of players to better understand their habits and debunk the stereotypical gamer profile (Williams, Yee, \& Caplan, S., 2008).

Numerous studies have documented the negative side effects. Gamers have sacrificed sleep, diet, hobbies, exercise and socializing in order to make time for playing (Young, 2009). In addition, depression and suicidal ideation have been associated with excessive digital gaming (Messias, Castro, Saini, Usman, \& Peeples, 2011). Researchers have also discovered that violent video games, typically played by a population of male gamers, generally caused an increase in violent and aggressive behavior (Lemmens, Valkenburg, \& Peter, 2011; Zhang, Cao, \& Tian, 2021). Lower psychosocial well-being was generally regarded as a reason for pathological involvement in online games (Lo, Wang, \& Fang, 2005; Seay \& Kraut, 2007), whereas aggressive behavior may be a consequence of gaming (Caplan, Williams, \& Yee, 2009). Furthermore, another study showed that increased Multiplayer Online Battle Arena (MOBA) gameplay was associated with poorer psychological well-being, specifically, there is a greater motivation to play as a means of escaping reality. They also found that an escapist motivation for playing is correlated with poor psychological well-being and low self-esteem (Goh, Jones, \& Copello, 2019). There was also a significant correlation with higher levels of play time and worsening psychological well-being (Goh, Jones, \& Copello, 2019). In fact, MMO games can lead to a condition called problematic internet use (PIU), also known as internet addiction (Morrison \& Gore, 2010; Torrez-Rodriguez, Griffiths, Carbonell, \& Oberest, U., 2018). Cole \& Hooley (2013) showed that high anxiety and absorption may be risk factors for PIU with the MMO gaming environment.

However, there were also studies looking at the positive effects of video games. One study explored video games and their benefit to veterans dealing with trauma (Carras et al., 2018). The veteran participants reported the games helped with managing moods and stress as well as helped with adaptive coping, well-being, and socialization. The authors concluded video games seemed to provide a form of "personal medicine" in their recovery. Another review article looked at video games and flourishing mental health (Jones, Scholes, Johnson, Katsikitis, \& Carras, 2014). The authors concluded that playing may have the potential to enhance life satisfaction and positive emotion. A specific form of gaming called augmented reality, such as Pokemon GO and Harry Potter: Wizards Unite, has been shown to be related to improved mental and physical health by providing virtual socialization and sustained exercise (Ellis et al., 2020). In addition, a recent study showed more time was spent playing video games during the pandemic and the authors qualitatively reported video games' impact on the players' well-being (Barr \& Copeland-Stewart, 2021). Open-ended questions allowed them to gain insight into the players' responses related to socialization and mental health. They concluded the players perceived video games to help maintain social contact, relieve stress, and provide mental stimulation. However, the findings were not quantitative, and there is still very little research in this area because the pandemic is very recent. In addition, there are no previous studies looking at and comparing the differences in the single-player and MMO players during this time period. This study aims to further explore the experiences and psychosocial well-being of those who play single and multiplayer video games specifically during the COVID-19 pandemic and comparing them to their pre-pandemic time.

\section{Methods}

\subsection{Overview}

Our study was conducted with the use of two online questionnaires. The questions were written in standard survey style and form (Martin, E., 2006; Roopa, S., \& Rani, M. S., 2012). Each questionnaire consisted of basic demographic questions, closed questions related to gaming habits and psychosocial well-being. The survey was distributed from June 28th, 2021, to July 29th, 2021. The time period of interest was the COVID-19 pandemic when most people were under lockdown or shelter-in-place orders until the present time. 


\subsection{Sample and Recruitment}

Participant recruitment was conducted over the internet with the use of the website Reddit.com, Facebook, various

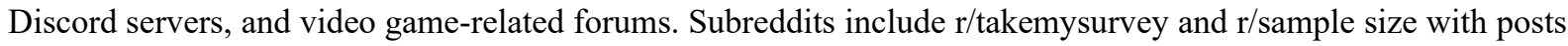
being targeted towards only those who play video games. Other subreddits include r/videogames, r/MMORPG, and $\mathrm{r} /$ LeagueofLegends. The surveys were also posted on video game-related forums such as dev.dota.com. Lastly, the survey was posted to Quora.com. Participants were informed that their responses would be kept completely anonymous, and participation was voluntary. The two surveys were posted separately with different wording to target their intended audience. All participants had the option to withdraw at any time prior to submitting their responses. Those who consented were directed to the questionnaire they chose. No incentive was provided for taking the survey. Participants were notified that they would not have to provide any identifiable information in the survey.

\subsection{The Survey}

The single-player questionnaire had 33 questions and had an average completion time of 12 minutes. The multiplayer video game questionnaire consisted of 38 questions and had an average completion time of 9 minutes. Demographic questions collected information that includes the participants' gender, age, employment, and student status. It also asked about shelter-in-place during the pandemic and for how long. In addition, questions about how many hours and days a week participants played video games were asked. Lastly, the survey included questions about extroversion and introversion, depression and anxiety, gaming motivations and psychosocial well-being.

\subsection{Mental and Social Well-Being}

Participants answered indicator questions about their mental and social well-being. Participants also answered direct questions about whether their mental and social well-being improved, worsened, or did not change while playing video games during the pandemic. The indicator questions were based on the definitions of mental health and social wellness from MentalHealth.gov, (a division of the U.S. Department of Health and Human Services) and the National Institutes of Health, respectively.

\subsection{Data Analysis}

Quantitative questionnaire data were analyzed using R Studio and various R packages. The Pearson chi-squared test was used to examine a majority of the data as most were categorical and measured between two different time periods. In addition, differences between single and multiplayer groups during the pandemic were also measured using the chi-squared test. The significance level was set at $p<0.05$. However, the $p$-values calculated for some of the findings were so exceptionally low that they were stated as $p<0.001$.

\section{Results}

For both the single-player and multiplayer video game surveys, the demographics of respondents were very similar (Table 1). The average age of the participants was 24 years old. The majority were male, self-reported as introverts, and approximately $40 \%$ have been diagnosed with anxiety or depression. The number of respondents for the single-player survey was 132 people, and 128 multiplayer respondents took the multiplayer survey. 
Table 1. Demographics of Single-Player and Multiplayer Respondents

\begin{tabular}{|c|c|c|}
\hline Characteristic & Single-Player $n=132(\%)$ & Multiplayer $n=128(\%)$ \\
\hline Age (Average) & $24.1 \mathrm{SD}+/-8$ & $24.5 \mathrm{SD}+/-11$ \\
\hline \multicolumn{3}{|l|}{ Gender } \\
\hline Male & $78(59.1)$ & $84(65.6)$ \\
\hline Female & $37(28)$ & $34(26.5)$ \\
\hline Non-Binary & $12(9.1)$ & $7(5.4)$ \\
\hline Prefer Not to Say & $5(3.7)$ & $3(2.3)$ \\
\hline \multicolumn{3}{|l|}{ Employment Status } \\
\hline Full Time & $40(30.3)$ & $37(28.9)$ \\
\hline Part-Time & $23(17.4)$ & $19(14.8)$ \\
\hline Not a Currently Working & $69(52.2)$ & $72(56.3)$ \\
\hline \multicolumn{3}{|l|}{ Student Status } \\
\hline Full Time & $59(44.6)$ & $61(47.6)$ \\
\hline Part-Time & $16(12.1)$ & $9(7.03)$ \\
\hline Not a Student & $57(43.2)$ & $58(45.3)$ \\
\hline \multicolumn{3}{|l|}{ Shelter-in-Place } \\
\hline Yes & $122(92.4)$ & $115(89.8)$ \\
\hline No & $10(7.6)$ & $13(10.1)$ \\
\hline Average Months, if Yes & 11.6 & 10.7 \\
\hline \multicolumn{3}{|l|}{$\begin{array}{l}\text { Average Days Per Week Playing } \\
\text { Video Games }\end{array}$} \\
\hline Before the Pandemic & $4.0 \mathrm{SD}+/-2.1$ & $4.2 \mathrm{SD}+/-2.1$ \\
\hline During the Pandemic & $5.2 \mathrm{SD}+/-1.7$ & $5.6 \mathrm{SD}+/-1.7$ \\
\hline \multicolumn{3}{|l|}{ Self-Reported Personality } \\
\hline Introvert & $107(81.1)$ & $99(77.3)$ \\
\hline Extrovert & $25(18.9)$ & $29(22.6)$ \\
\hline $\begin{array}{l}\text { Diagnosed With } \\
\text { Depression }\end{array}$ & & \\
\hline Yes & $52(39.4)$ & $52(40.6)$ \\
\hline No & $80(60.6)$ & $76(59.3)$ \\
\hline
\end{tabular}




\subsection{Days and Hours Playing Video Games}

During the pandemic, there was a $105 \%$ increase in participants who spent 5 or more hours a day playing single-player video games as compared to before the pandemic. This shows a clear increase in playtime for a majority of single-player participants during the pandemic. A similar trend was seen with the number of days per week participants reported playing video games. During the pandemic, there was a $66 \%$ increase in participants who played single-player video games 5 or more days a week.

For multiplayer gamers, the trend was even larger. There was a $129 \%$ increase in participants who played 5 or more hours a day of MMO video games during the pandemic as compared to before. Again, the trend continued with days played per week. There was a 57\% increase in participants who played MMO games 5 or more days a week during the pandemic (Figure 1).

Chi-square tests of independence were performed to examine the relation between time period (before or during the pandemic) and amount of time played. The tests were run on responses of both the single-player and multiplayer groups. Results are displayed in Table 2.

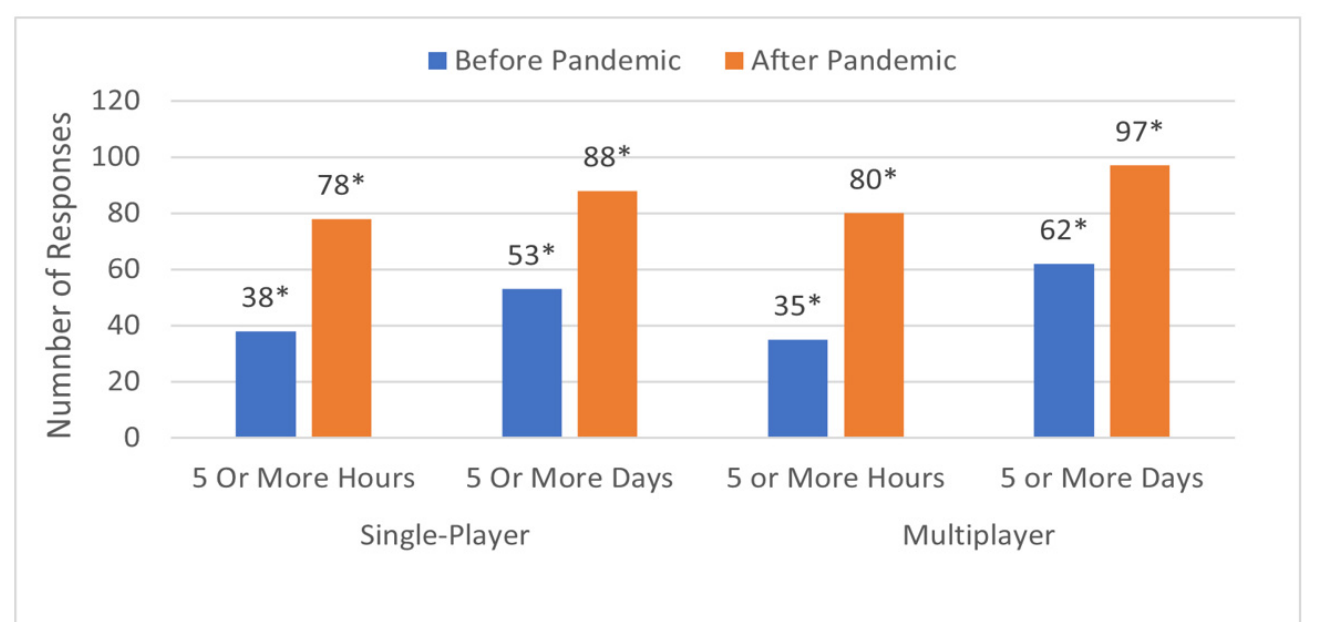

Figure 1. Hours played per day and days played per week: single-player and multiplayer

$* \mathrm{p}<0.001$ Every change was significant

Table 2. Comparison of Single-Player and Multiplayer Groups Before and During Pandemic

\section{Hours and Days Played \\ Chi-Square Tests of Independence}

\section{Single-Player}

5 or More Hours Per Day

$$
\begin{aligned}
& X^{2}(1)=24.60 \\
& p<0.001 \\
& n=132
\end{aligned}
$$

5 or More Days Per Week

$$
\begin{aligned}
& X^{2}(1)=18.65 \\
& p<0.001 \\
& n=132
\end{aligned}
$$

\section{Multiplayer}

5 or More Hours Per Day

$$
\begin{aligned}
& X^{2}(1)=31.97 \\
& p<0.001 \\
& n=128
\end{aligned}
$$

5 or More Days Per Week

$$
\begin{aligned}
& X^{2}(1)=20.33 \\
& p<0.001 \\
& n=128
\end{aligned}
$$




\subsection{Motivations for Playing}

Questions regarding motivations for playing video games before and during the pandemic were collected: to decrease stress, to decrease anxiety, to feel happier, to get away from real life, just for fun, to be a different person, other. Figures 2 and 3 depict motivations that significantly increased during the pandemic for these players. The single-player data showed a statistically significant increase in the number of those who played single-player video games to decrease anxiety and to get away from real life. The p-values are $p<0.001$ and $p<0.01$, respectively. In addition, $92 \%$ reported feeling relaxed while playing single-player video games.

Multiplayer participants did not exhibit any statistically significant changes to the previously mentioned motivations. However, there was a statistical increase in the motivation to socialize via MMO games during the pandemic, $p<0.001$ (Figure 3). In addition, $66 \%$ of the participants stated playing multiplayer video games gave them a sense of belonging and $83 \%$ reported feeling collaborative in MMO games.

Chi-square tests of independence were performed to examine the relation between time period (before or during the pandemic) and motivation for playing video games. The tests were run on responses of both the single-player and multiplayer groups. Results are displayed in Table 3.

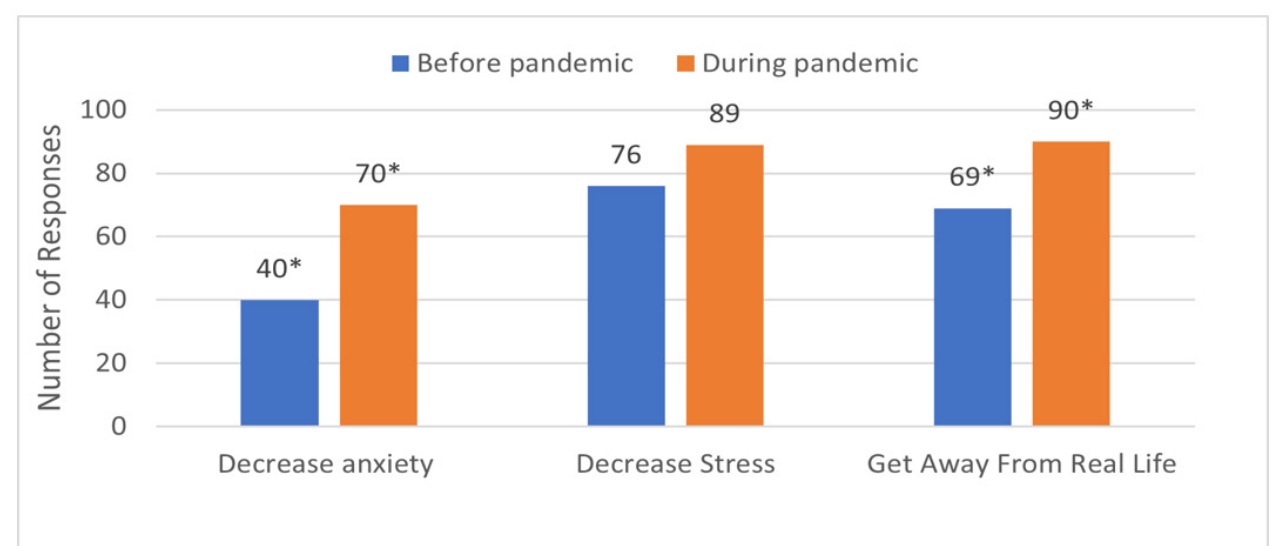

Figure 2. Motivations for playing single-player video games before and during the pandemic

$$
* \mathrm{p}<0.01
$$

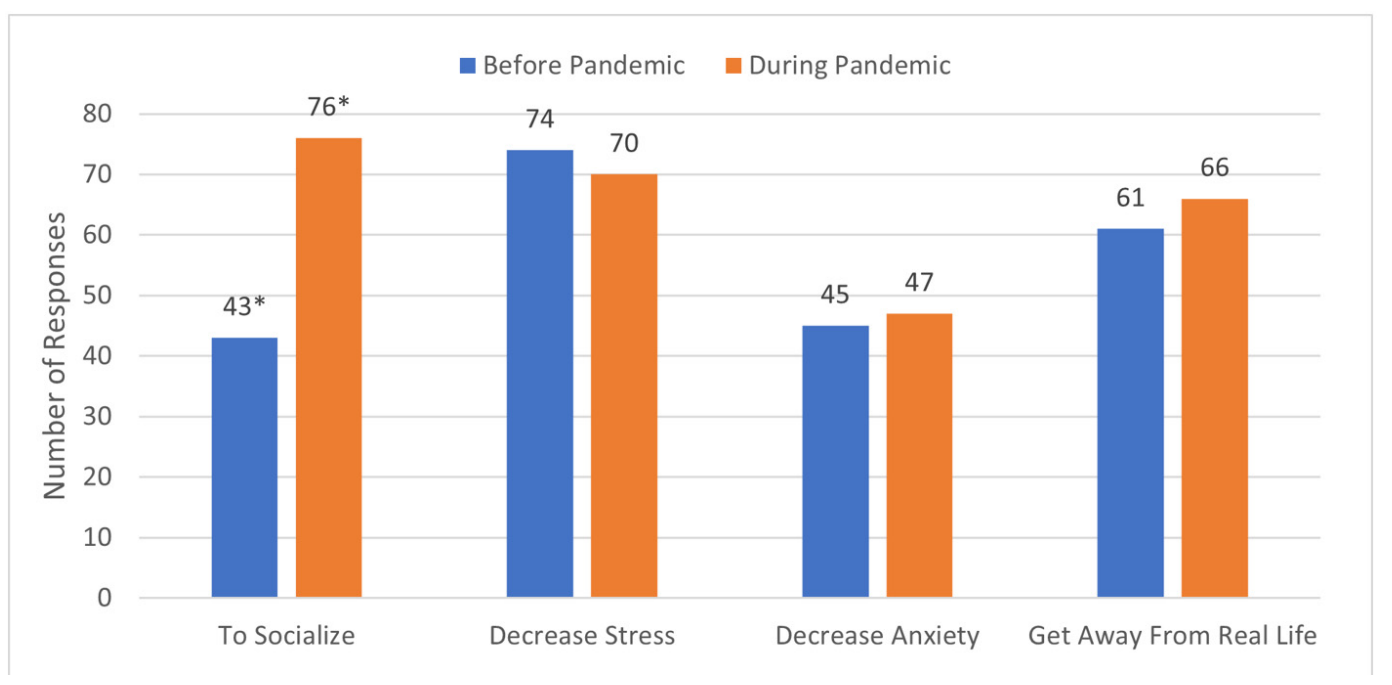

Figure 3. Motivations for playing multiplayer video games before and during the pandemic

$$
* \mathrm{p}<0.01
$$


Table 3. Comparison of Motivations for Playing Before and During the Pandemic Among Single-Player and Multiplayer Groups

\begin{tabular}{|c|c|}
\hline Motivation & Chi-Square Tests of Independence \\
\hline \multicolumn{2}{|l|}{ Single-Player } \\
\hline Decrease Anxiety & $\begin{array}{l}X^{2}(1)=14.02 \\
p<0.001 \\
n=132\end{array}$ \\
\hline Decrease Stress & $\begin{array}{l}X^{2}(1)=2.73 \\
p=0.1 \\
n=132\end{array}$ \\
\hline Get Away From Real Life & $\begin{array}{l}X^{2}(1)=6.97 \\
p<0.01 \\
n=132\end{array}$ \\
\hline \multicolumn{2}{|l|}{ Multiplayer } \\
\hline To Socialize & $\begin{array}{c}X^{2}(1)=17.1 \\
p<0.001 \\
n=128\end{array}$ \\
\hline Decrease Anxiety & $\begin{array}{l}X^{2}(1)=0.25 \\
p=0.61 \\
n=128\end{array}$ \\
\hline Decrease Stress & $\begin{array}{l}X^{2}(1)=0.07 \\
p=0.79 \\
n=128\end{array}$ \\
\hline Get Away From Real Life & $\begin{array}{l}X^{2}(1)=0.39 \\
p=0.53 \\
n=128\end{array}$ \\
\hline
\end{tabular}

\subsection{Mental Health and Social Well-Being}

Data was collected on mental health and social well-being during the pandemic through both indicator questions and direct inquiry. Indicator questions were based on the National Institute of Health and MentalHealth.gov., a division of the US Department of Health and Human Services. Approximately $40 \%$ of both single and multiplayer respondents reported having been diagnosed with either depression or anxiety at some point in their lives.

The single-player and MMO responses for mental health during the pandemic yielded similar results (Figure 4). Indicators of worsening mental health were asked: over or undereating, irregular sleep schedule, pulling away from people or usual activities, low energy, feeling numb or nothing matters, having unexplained aches and pains, and feeling helplessness or hopelessness. Approximately 40-50\% of respondents in both single and multiplayer reported experiencing these feelings and behavior more often, except for having unexplained aches and pains, which only approximately $26 \%$ reported having. However, $47 \%$ of single and $31 \%$ of MMO players report improved mental well-being while playing video games during the pandemic. 


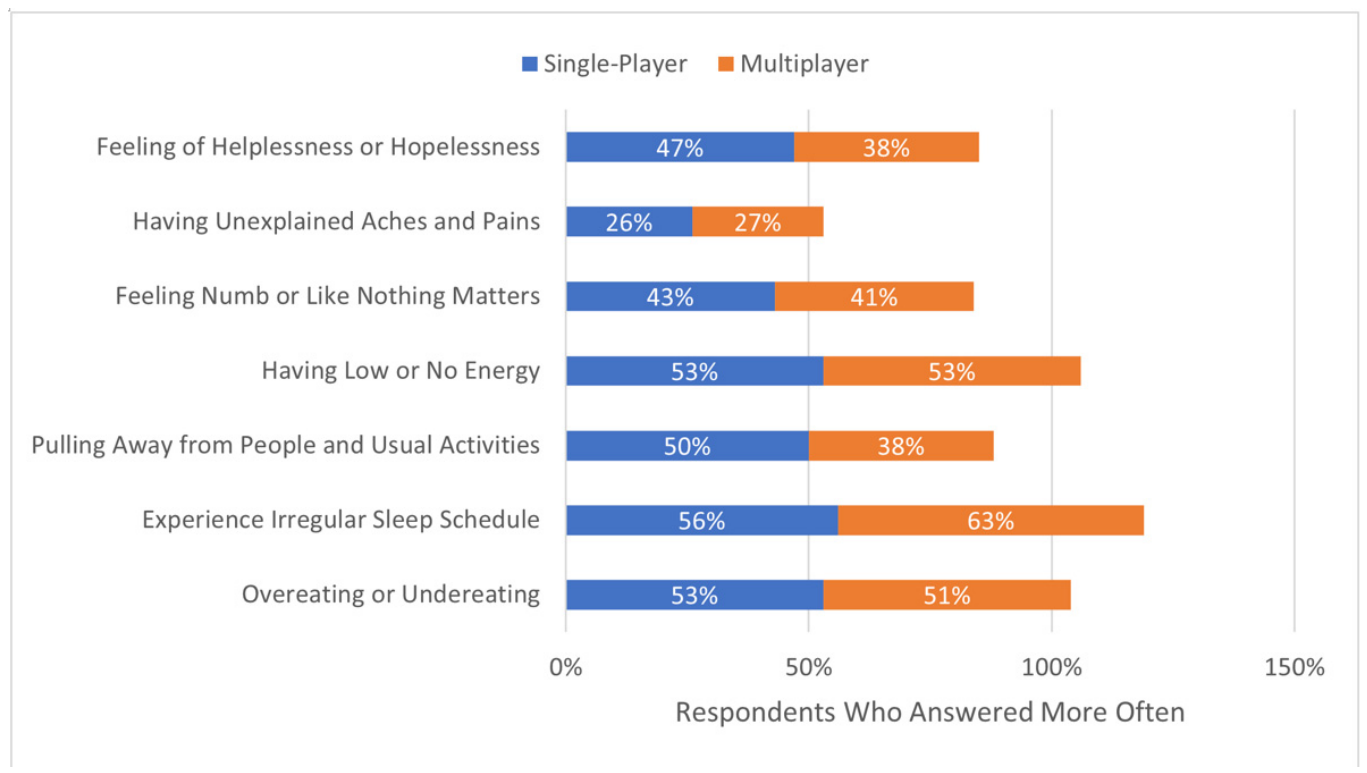

Figure 4. Indicators of mental health: single-player vs. multiplayer during the pandemic

Indicators of social well-being during the pandemic were also asked: exercise, eat healthy, talk with friends and family, learn something new, and give or volunteer for a cause. Responders were given choices of more often, less often, or no change. Approximately $33 \%$ chose more often, $33 \%$ less often, and $33 \%$ chose no change. Those who chose less often indicated a lower level of social well-being. Figure 5 displayed similar results between single-player and MMO respondents who selected the less often option. There were no significant differences in responses between single-player and MMO players.

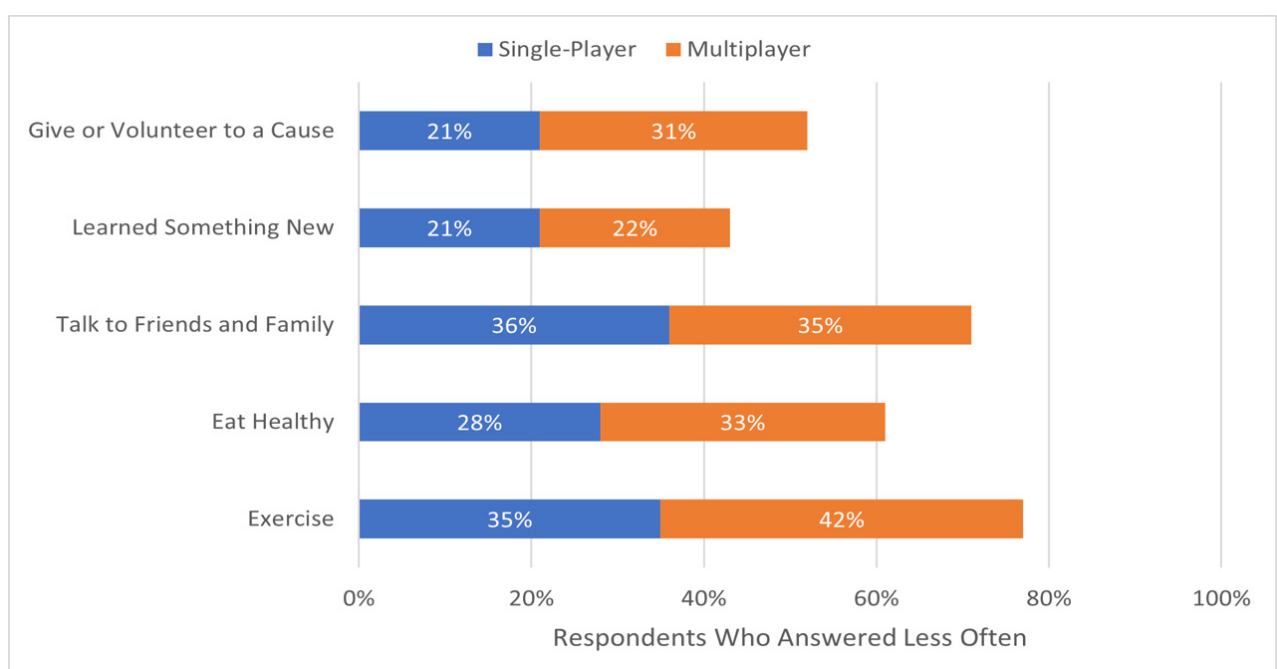

Figure 5. Indicators of social well-being: single-player vs. multiplayer during the pandemic

When asked directly about their mental health and social well-being while playing video games during the pandemic, respondents tended to answer more positively. Both answered that their mental and social well-being are improved while playing video games. Not surprisingly, more MMO than single-player gamers reported improved social well-being while playing video games, likely due to the collaboration and interaction with others. In fact, $61 \%$ of introverts in the multiplayer survey indicated that playing MMO games did satisfy their need to socialize.

\section{Discussion}

Video games are a popular medium of entertainment for many individuals, providing a way to fill their free time before and during the COVID-19 pandemic. The surveys we conducted provide insight into the experiences and psychosocial well-being of those who play single- and multiplayer video games during the recent global health crisis. 
With $92 \%$ of single-player and 90\% of MMO players reporting shelter-in-place for an average of 11.6 and 10.7 months, respectively, it is not surprising to see a significant rise in the number of hours and days playing both types of games. There may be a loss of a job that opens more hours in the day to play, or a lack of in-person school or work that allows individuals to stay up longer. $53 \%$ of single-player and $56 \%$ of multiplayer gamers report not working, but they could be students staying at home studying virtually with more time to play.

We also looked at motivations for playing video games during the pandemic. For single-player respondents there was a significant increase in choosing to decrease anxiety and to get away from real life as motivations for playing. An overwhelming majority, $92 \%$, reported feeling relaxed while playing single-player video games. This is consistent with previous studies indicating players play video games to reduce stress and anxiety (Barr \& Copeland-Stewart, 2021). In contrast, we saw a significant increase in the number of MMO players who chose to socialize as their motivation to play during the pandemic, and not necessarily to decrease stress or anxiety. There may be a difference in motivations in single-player and multiplayer gamers in terms of how they use video games to cope with lockdown.

Psychosocial well-being was assessed with indicator questions and direct inquiry. Approximately $40 \%$ of single and multiplayer respondents reported having had a diagnosis of anxiety or depression. The lifetime prevalence of depression reported before the pandemic was $15 \%$ in men and $24 \%$ in women (Kessler, R. et al., 2010). During the pandemic, $40-50 \%$ of both types of gamers reported experiencing behaviors consistent with worsening mental health. One-third of both groups also reported decreased social well-being based on indicator questions provided by the NIH. However, when asked directly about their psychosocial well-being while playing video games, both groups tended to respond more positively. They reported feeling more relaxed while playing and their mental state was improved. This is consistent with the previous study showing video games can help with trauma in veterans (Carras et al., 2018). Similarly, we are collectively experiencing the trauma of the COVID-19 pandemic. In addition, MMO players benefited from online social interaction, sometimes with those in different countries and time zones. As a result of social interaction and collaboration, more MMO players compared to single-player reported improved social well-being while playing.

\section{Conclusion}

Based on these surveys, we can possibly conclude that gamers can look to single-player video games to help with relaxation, stress reduction, and perhaps an improvement in mental health during the pandemic while playing multiplayer games to increase social interaction and perhaps improve social well-being.

\section{Limitations and Future Direction}

There were some limitations to our study. One such limitation was the design of the questionnaire used in this study. The questionnaire required participants to remember events and behaviors that happened up to 1 year prior to taking the survey. This could result in recall bias to a participant's response to the questions. Another limitation is self-selection bias as the people who took the survey are people who opted to take the survey because they enjoy playing video games. Another limitation was that our study was a cross-sectional study, so we were not able to observe the long-term effects of video games on players during the pandemic. One strength in the data collection was the online forum allowed for individuals to participate from many different countries and the anonymity helped facilitate open and honest responses. Further research is needed to explore the long-term effects of video games during the pandemic after everyone has returned to a pre-pandemic state. As more people are spending time online in the virtual world, additional research will contribute toward a more nuanced understanding of video games.

\section{Acknowledgements}

I want to thank Andrew Savoy from the University of Chicago for his advice and mentoring, and Polygence Research Academy for the opportunity to perform research in the field of psychology.

\section{References}

Barr, M., \& Copeland-Stewart, A. (2021). Playing Video Games During the COVID-19 Pandemic and Effects on Players' Well-Being. Games and Culture. https://doi.org/10.1177/15554120211017036

Caplan, S., Williams, D., \& Yee, N. (2009). Problematic Internet Use and Psychosocial Well-being among MMO players. Computers in Human Behavior, 25(6), 1312-1319. https://doi.org/10.1016/j.chb.2009.06.006

Carras, M., Kalbarczyk, A., Wells K., Banks J., Gillespie, C., \& Latkin, C. (2018). Connection, Meaning, and Distraction: A Qualitative Study of Video Game Play and Mental Health Recovery in Veterans Treated for 
Mental and/or Behavioral Health Problems. Social Science \& Medicine, 216, 124-132. https://doi.org/10.1016/j.socscimed.2018.08.044

Clement, J. (2021). Number of Video Gamers Worldwide 2021, by Region. Statistica Research \& Analysis. Retrieved from https://www.statista.com/statistics/293304/number-video-gamers/

Cole Sadie, H., \& Hooley Jill, M. (2013). Clinical and Personality Correlates of MMO gaming: Anxiety and Absorption in Problematic Internet Use. Social Science Computer Review, 31(4), 424-436. https://doi.org/10.1177/0894439312475280

Das, A. (2021). Valorant Player Count: How Many People Still Play the Riot Games Fps. AFK Gaming.

Ellis, L., Lee, M., Ijaz, K., Smith, J., Braithwaite J., \& Yin, K. (2020). COVID-19 as 'Game Changer' for the Physical Activity and Mental Well-Being of Augmented Reality Game Players During the Pandemic: Mixed Methods Survey Study. Journal of Medical Internet Research, 22(12), e25117. https://doi.org/10.2196/25117

Epstein, A. (2020). Game on: HOW Covid-19 Became the Perfect Match for Gamers. World Economic Forum.

Goh, C., Jones, C., \& Copello, A. (2019). A Further Test of the Impact of Online Gaming on Psychological Wellbeing and the Role of Play Motivations and Problematic Use. Psychiatric Quarterly, 90, 747-760. https://doi.org/10.1007/s11126-019-09656-x

Hamstead, C. (2021). Warzone Player Count: How Many People Play Warzone? GGRecon.

How Many People Play CS:GO in 2021 [15 CS:GO Statistics \& Facts]. How Many People Play Counter-Strike [15 CS:GO Statistics and Facts 2021], 5 Mar. 2021.

Jones, C., Scholes, L., Johnson D., Katsikitis M., \& Carras M. (2014). Gaming Well: Links between Videogames and Flourishing Mental Health. Frontiers in Psychology, 5, 1-8. https://doi.org/10.3389/fpsyg.2014.00260

Kessler Ronald et al. (2010). Age Differences in Major depression: Results from the National Comorbidity

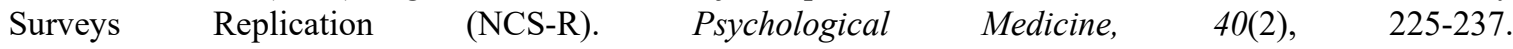
https://doi.org/10.1017/S0033291709990213

Lemmens, J. S., Valkenburg, P. M., \& Peter, J. (2011). The Effects of Pathological Gaming on Aggressive Behavior. Journal of Youth and Adolescence, 40(1), 38-47. https://doi.org/10.1007/s10964-010-9558-x

Lo, S., Wang, C., \& Fang, W. (2005). Physical Interpersonal Relationships and Social Anxiety Among Online Game Players. CyberPsychology and Behavior, 8, 15-20. https://doi.org/10.1089/cpb.2005.8.15

Martin, E. (2006). Survey Questionnaire Construction. Research Report Series. Survey Methodology \#2006-13. Director's Office U.S. Census Bureau. Washington D.C. 20233.

Messias, E., Castro, J., Sanni, A., Usman, M., \& Peeples, D. (2011). Sadness, Suicide, and their Association with Video Game and Internet Overuse Among Teens: Results from the Youth Risk Behavior Study 2007 and 2009. Suicide and Life-Threatening Behavior, 41(3), 307-315. https://doi.org/10.1111/j.1943-278X.2011.00030.x

Morrison, C. M., \& Gore, H. (2010). The Relationship Between Excessive Internet Use and Depression: A Questionnaire-Based Study of 1,319 Young People and Adults. Psychopathology, 43, 121-126. https://doi.org/10.1159/000277001

Roopa, S., \& Rani M. S. (2012). Questionnaire Designing for a Survey. Continuing Education.

Scott, J., \& Porter-Armstrong, A. (2013). Impact of Multiplayer Online Role-Playing Games upon the Psychosocial Well-being of Adolescents and Young Adults: Reviewing the Evidence. Psychiatry Journal, 2013. https://doi.org/10.1155/2013/464685

Seay, A. F., \& Kraut, R. E. (2007). Project Massive: Self-regulation and Problematic Use of Online Gaming. In CHI 2007: Proceedings of the ACM conference on Human Factors in Computing Systems (pp. 829-838). New York: ACM Press. https://doi.org/10.1145/1240624.1240749

Smith, N. (2020). The Giants of the Video Game Industry Have Thrived in the Pandemic. Can the Success Continue? The Washington Post, WP Company.

Torres-Rodriguez, A., Griffiths, M., Carbonell, X., \& Oberst, U. (2018). Internet Gaming Disorder in Adolescence: Psychological Characteristics of a Clinical Sample. Journal of Behavioral Addictions, 7(3), 707-718. https://doi.org/10.1556/2006.7.2018.75

U.S. Department of Health and Human Services. (2021). Social Wellness Toolkit. National Institutes of Health. 
U.S. Department of Health and Human Services. (2020). What Is Mental Health? MentalHealth.gov.

Williams, D., Yee, N., \& Caplan, S. (2008). Who Plays, How Much, and Why? Debunking the Stereotypical Gamer Profile. Journal of Computer-Mediated Communication, 13(4), 993-1018. https://doi.org/10.1111/j.1083-6101.2008.00428.x

Yee, N. (2006). Motivations for Play in Online Games. CyberPsychology \& Behavior, 9(6), 772-775. https://doi.org/10.1089/cpb.2006.9.772

Young, K. (2009). Understanding Online Gaming Addiction and Treatment Issues for Adolescents. The American Journal of Family Therapy, 37(5), 355-372. https://doi.org/10.1080/01926180902942191

Zhang, Q., Cao, Y., \& Tian, J. (2021). Effects of Violent Video Games on Aggressive Cognition and Aggressive Behavior. Cyberpsychology, Behavior, and Social Networking, 24(1), 5-10. https://doi.org/10.1089/cyber.2019.0676

\section{Copyrights}

Copyright for this article is retained by the author(s), with first publication rights granted to the journal.

This is an open-access article distributed under the terms and conditions of the Creative Commons Attribution license (http://creativecommons.org/licenses/by/4.0/). 